\title{
Early primary renal tumor response predicts clinical outcome in patients with primary unresectable renal cell carcinoma with synchronous distant metastasis receiving molecularly targeted therapies
}

\author{
KOSUKE UEDA, SHIGETAKA SUEKANE, KIYOAKI NISHIHARA, HIROKI SUEKANE, \\ NAOYUKI OGASAWARA, HIROFUMI KUROSE, KATSUAKI CHIKUI, KAZUHISA EJIMA, \\ SHUNSUKE SUYAMA, MAKOTO NAKIRI, MITSUNORI MATSUO and TSUKASA IGAWA \\ Department of Urology, Kurume University School of Medicine, Kurume, Fukuoka 830-0011, Japan
}

Received February 8, 2017; Accepted April 13, 2017

DOI: $10.3892 / \mathrm{mco} .2017 .1294$

\begin{abstract}
The aim of the present study was to investigate the prognostic factors for patients with primary unresectable renal cell carcinoma (RCC) with synchronous distant metastasis receiving molecularly targeted therapies. A total of 26 patients with primary unresectable RCC with synchronous distant metastasis underwent molecularly targeted therapies at the Kurume University Hospital (Kurume, Japan) between March 2008 and March 2016. Early primary renal tumor response was evaluated at 8-12 weeks after the introduction of molecularly targeted therapy and a $10 \%$ decrease in the diameter of primary renal tumor was used as the cut-off value. The median overall survival from the initiation of first-line molecularly targeted therapy was 18.3 months. Univariate analyses for various factors identified early primary renal tumor response $(\mathrm{P}=0.0004)$ and best response to first-line treatment $(\mathrm{P}=0.0002)$ as prognostic variables. Multivariate analyses also identified early primary renal tumor response $(\mathrm{P}=0.0099)$ and best response to first-line treatment $(\mathrm{P}=0.0054)$ as independent prognostic factors. A comparison of clinical characteristics between the group with $\geq 10 \%$ shrinkage and the group with disease progression or $<10 \%$ shrinkage revealed that the number of metastatic sites and pretreatment monocyte-to-lymphocyte ratio tended to be predictive factors for primary renal tumor response. These results suggest that early primary renal tumor shrinkage is highly variable for patients with primary unresectable RCC with synchronous distant metastasis receiving molecularly targeted therapies.
\end{abstract}

Correspondence to: Dr Kosuke Ueda, Department of Urology, Kurume University School of Medicine, 67 Asahi-machi, Kurume 830-0011, Japan

E-mail: ueda_kousuke@med.kurume-u.ac.jp

Key words: early tumor response, primary unresectable renal cell carcinoma, molecularly targeted therapy, prognosis, metastasis

\section{Introduction}

Over the last several years, the therapeutic strategy for metastatic renal cell carcinoma (mRCC) has included the administration of molecularly targeted agents, such as multitargeted tyrosine kinases inhibitors and mammalian target of rapamycin inhibitors, rather than immunotherapy as first-line therapy. In the targeted therapy era, several studies have reported an overall survival (OS) benefit in mRCC patients receiving cytoreductive nephrectomy $(\mathrm{CN})(1,2)$. However, certain patients may be unable to receive $\mathrm{CN}$ due to locally advanced disease, multiple metastases or poor performance status (PS) at initial diagnosis. These patients occasionally receive molecularly targeted therapies as initial treatment. Several studies have demonstrated that early primary tumor shrinkage predicted a better overall primary tumor response $(3,4)$. These studies validated $10 \%$ primary tumor shrinkage as a reliable early predictor of outcome in mRCC patients receiving vascular endothelial growth factor (VEGF)-targeted therapies, and this may provide a practical measure to guide therapeutic decisions (4). However, there is no consensus on the optimal treatment of mRCC patients with synchronous distant metastasis.

The aim of the present study was to investigate the prognostic factors for patients with primary unresectable RCC with synchronous distant metastasis receiving molecularly targeted therapies.

\section{Patients and methods}

Patient evaluation. A total of 26 patients with primary unresectable RCC with synchronous distant metastasis underwent molecularly targeted therapies at the Kurume University Hospital (Kurume, Japan) between March 2008 and March 2016. These patients were considered unable to receive $\mathrm{CN}$ due to locally advanced disease, multiple metastases and/or poor PS at initial diagnosis. Clinical data, including age, gender, Memorial Sloan-Kettering Cancer Center (MSKCC) risk classification, $\mathrm{CN}$ status, tumor stage, lymph node stage, number 
of metastatic sites, site of metastasis, anemia, pretreatment C-reactive protein level, pretreatment neutrophil-to-lymphocyte ratio, pretreatment monocyte-to-lymphocyte ratio (MLR) and pretreatment platelet-to-lymphocyte ratio were retrieved from medical records and retrospectively analyzed.

Prior to the initiation of molecularly targeted therapy, radiological evaluations were performed for all patients by computed tomography (CT). Tumor measurements were conducted by CT prior to the initiation of treatment. Early primary renal tumor response was evaluated at 8-12 weeks after the introduction of molecularly targeted therapy and a $10 \%$ decrease in the diameter of the primary renal tumor was used as the cut-off value based on previous reports $(3,4)$. Tumor response was evaluated according to the Response Evaluation Criteria in Solid Tumours (RECIST), version 1.1 (https://ctep.cancer.gov/protocoldevelopment/docs/recist_ guideline.pdf).

Statistical analysis. The OS from the initiation of molecularly targeted therapy to the date of death was determined using the Kaplan-Meier method and analyzed using the log-rank test. To identify the prognostic factors associated with OS, Cox proportional hazards regression was used. Univariate and multivariate analyses were performed for independent prognostic factors for OS. The associations between groups were compared using the Chi-squared test, Fisher's exact test or Student's t-test. All the statistical analyses were performed using JMP software, version 11 (SAS Institute, Inc., Cary, $\mathrm{NC}$, USA) and a value of $\mathrm{P}<0.05$ was considered to indicate a statistically significant difference. This study was approved by the Ethics Review Committee of the Kurume University School of Medicine.

\section{Results}

Patient characteristics. The patient characteristics are summarized in Table I. All the patients had metastatic disease at diagnosis. The median patient age was 69 years (range, 47-81 years) and the majority of the patients were male (73.1\%). All the MSKCC risk groups were represented among the patients, with $57.7 \%$ of the patients being classed as intermediate- and $42.3 \%$ as poor-risk. The majority of the patients had lung metastases, and half of all patients had lymph node metastases. A total of 17 (65.4\%) patients had $\geq 2$ metastatic sites at diagnosis; 5 (19.2\%) patients underwent $\mathrm{CN}$ during the course of treatment.

Treatment. The profile of first-line molecularly targeted therapy and pretreatment laboratory data are shown in Table II. The majority of the patients received sunitinib (69.2\%) as the first-line molecularly targeted agent.

Survival analysis. The OS curve for all patients is shown in Fig. 1. The median OS from the start of first-line molecularly targeted therapy was 18.3 months [95\% confidence interval (CI): 4.0-32.2 months]. Cox proportional hazards regression was used to identify the associations with OS among known prognostic factors (Table III). Univariate analyses for various factors revealed early primary renal tumor response [hazard ratio (HR) $=10.956,95 \%$ CI: $2.691-74.262, \mathrm{P}=0.0004)$
Table I. Characteristics of 26 patients with primary unresectable renal cell carcinoma with synchronous distant metastasis receiving molecularly targeted therapies.

\begin{tabular}{|c|c|}
\hline Patient and tumor characteristics & No. $(n=26)$ \\
\hline Age, years (range) & $69(47-81)$ \\
\hline \multicolumn{2}{|l|}{ Gender } \\
\hline Male & 19 \\
\hline Female & 7 \\
\hline \multicolumn{2}{|l|}{ ECOG PS } \\
\hline 0,1 & 17 \\
\hline$\geq 2$ & 9 \\
\hline \multicolumn{2}{|l|}{ MSKCC risk classification } \\
\hline Favorable & 0 \\
\hline Intermediate & 15 \\
\hline Poor & 11 \\
\hline Cytoreductive nephrectomy & 5 \\
\hline \multicolumn{2}{|l|}{ Clinical T stage } \\
\hline $\mathrm{T} 1$ & 3 \\
\hline $\mathrm{T} 2$ & 4 \\
\hline $\mathrm{T} 3$ & 7 \\
\hline $\mathrm{T} 4$ & 12 \\
\hline \multicolumn{2}{|l|}{$\mathrm{N}$ stage } \\
\hline No & 12 \\
\hline N1 & 4 \\
\hline $\mathrm{N} 2$ & 10 \\
\hline \multicolumn{2}{|l|}{ Number of metastatic sites } \\
\hline 1 & 9 \\
\hline$\geq 2$ & 17 \\
\hline \multicolumn{2}{|l|}{ Site of metastasis } \\
\hline Lung & 21 \\
\hline Bone & 8 \\
\hline Liver & 5 \\
\hline Brain & 3 \\
\hline Others & 4 \\
\hline \multicolumn{2}{|l|}{ Anemia } \\
\hline No & 11 \\
\hline Yes & 15 \\
\hline NLR, median (range) & $3.65(1.7-22.6)$ \\
\hline MLR, median (range) & $0.32(0.16-1.07)$ \\
\hline PLR, median (range) & $217.4(107.7-494.4)$ \\
\hline CRP, mg/dl, median (range) & $1.56(0.13-15.66)$ \\
\hline
\end{tabular}

ECOG PS, Eastern Cooperative Oncology Group performance status; MSKCC, Memorial SloanKettering Cancer Center; NLR, neutrophil-to-lymphocyte ratio; MLR, monocytetolymphocyte ratio; PLR, platelet-to-lymphocyte ratio; CRP, C-reactive protein.

and best response to first-line treatment $(\mathrm{HR}=26.067$, 95\% CI: 4.111-510.816, $\mathrm{P}=0.0002)$ as prognostic variables. Multivariate analyses also identified early primary renal tumor response (HR=8.060, 95\% CI: 1.644-58.233, $\mathrm{P}=0.0099)$ and best response to first-line treatment $(\mathrm{HR}=12.580$, 
Table II. Profile of molecularly targeted therapy.

\begin{tabular}{lr}
\hline Patient and tumor characteristics & No. $(\mathrm{n}=26)$ \\
\hline First-line treatment & 18 \\
Sunitinib & 3 \\
Pazopanib & 2 \\
Sorafenib & 2 \\
Temsirolimus & 1 \\
Axitinib & \\
Best response to first-line treatment & 3 \\
PR & 15 \\
SD & 8 \\
PD & \\
\hline
\end{tabular}

PR, partial response; $\mathrm{SD}$, stable disease; $\mathrm{PD}$, progressive disease.

95\% CI: $1.971-247.566, \mathrm{P}=0.0054)$ as independent prognostic factors

Patients in the CN group tended to have a longer OS compared with patients in the non- $\mathrm{CN}$ group. However, there was no significant difference between the $\mathrm{CN}$ and the non- $\mathrm{CN}$ groups $(\mathrm{P}=0.079)$.

Early primary renal tumor response was analyzed for its association with OS (Fig. 2). The median OS was 37.1 months in the group with $\geq 10 \%$ shrinkage on the first follow-up CT and 4.1 months in the group with progression or $<10 \%$ shrinkage. There was a significant difference in the OS rates between the two groups $(\mathrm{P}=0.0005)$.

Table IV shows a comparison of baseline characteristics between the group with $\geq 10 \%$ shrinkage and the group with progression or $<10 \%$ shrinkage on the first-follow up CT. Metastasis to $\geq 2$ organs $(\mathrm{P}=0.0313)$ and pretreatment MLR $(\mathrm{P}=0.0459)$ were higher in the group with progression or $<10 \%$ shrinkage compared with in the group with $\geq 10 \%$ shrinkage. The patients with progression or $<10 \%$ shrinkage on the first follow-up CT tended to have lymph node metastasis $(\mathrm{P}=0.0513)$ and bone metastasis $(\mathrm{P}=0.0556)$, but there was no significant difference between the two groups.

\section{Discussion}

Recent reports have suggested that up to $17 \%$ of patients with $\mathrm{RCC}$ have metastatic disease at diagnosis (5). $\mathrm{CN}$ is often indicated as part of an integrated management strategy for mRCC. However, certain patients cannot receive $\mathrm{CN}$ due to locally advanced tumor, multiple metastatic disease or poor PS at initial diagnosis. For patients with primary unresectable RCC with synchronous distant metastasis, molecularly targeted therapies are introduced as initial treatment. However, there have been few reports of prognostic factors for unresectable RCC with synchronous distant metastasis.

In the present study, early primary renal tumor response and best response to first-line treatment were reliable predictors of clinical outcome. Seidel et al (6) and Miyake et al (7) suggested that early tumor shrinkage is a prognostic tool, and more extensive tumor shrinkage is associated with a favorable

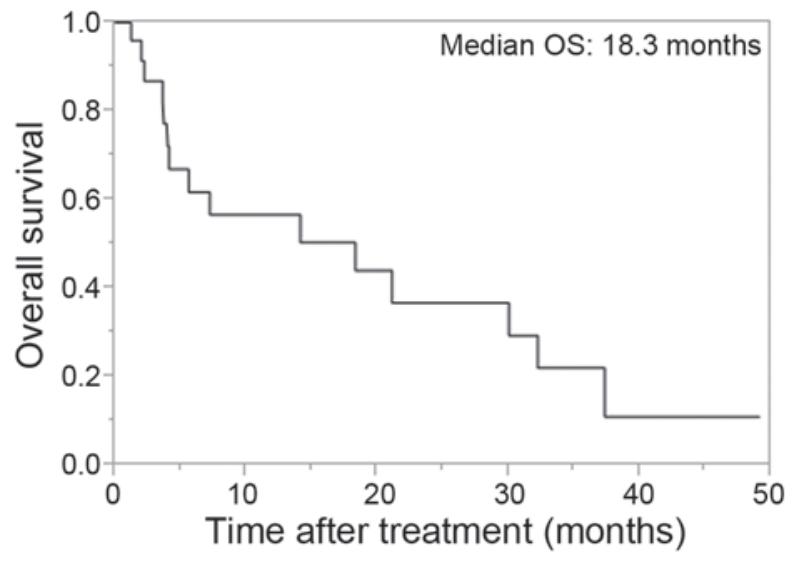

Figure 1. Overall survival (OS) in patients with primary unresectable renal cell carcinoma with distant metastasis receiving molecularly targeted therapies.

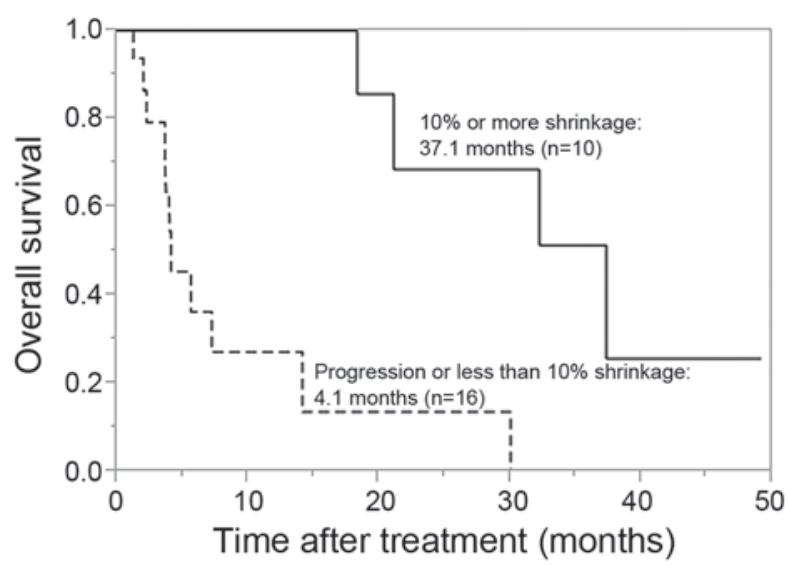

Figure 2. Overall survival in patients with primary unresectable renal cell carcinoma with distant metastasis receiving molecularly targeted therapies stratified according to early primary tumor response. Patients with $\geq 10 \%$ shrinkage on the first follow-up computed tomography had a significantly longer overall survival compared with patients exhibiting disease progression or $<10 \%$ shrinkage $(\mathrm{P}=0.0005)$.

prognosis. Furthermore, Krajewski et al (8) demonstrated that a $10 \%$ tumor shrinkage is validated as a reliable early predictor of outcome in mRCC patients receiving VEGF-targeted therapies. Although these studies support the present findings, patients receiving $\mathrm{CN}$ were included in the majority of these studies.

RECIST is the most widely accepted method for objectively assessing the response to therapy in RCCs treated with molecularly targeted therapies (9). However, the proportion of patients not receiving $\mathrm{CN}$ who exhibited tumor shrinkage of $>30 \%$ following molecularly targeted therapies [partial response (PR)] is low, suggesting the limited utility of best response according to RECIST. Previous studies on primary renal tumors treated with molecularly targeted therapies have reported a PR rate of $6 \%$ (3). Several studies have demonstrated that molecularly targeted agents frequently produce attenuation, which is not evaluated using RECIST, and has led several authors to recommend alternative systems $(10,11)$.

In our analysis, early primary renal tumor response and best response to first-line treatment were independent 
Table III. Univariate and multivariate analyses of overall survival in patients with primary unresectable renal cell carcinoma with distant metastasis receiving molecularly targeted therapies.

\begin{tabular}{|c|c|c|c|c|}
\hline \multirow[b]{2}{*}{ Parameters } & \multicolumn{2}{|c|}{ Univariate analysis } & \multicolumn{2}{|c|}{ Multivariate analysis } \\
\hline & Hazard ratio $(95 \% \mathrm{CI})$ & P-value & Hazard ratio $(95 \% \mathrm{CI})$ & P-value \\
\hline \multicolumn{5}{|l|}{ Age, years } \\
\hline$<69$ & 1 & & & \\
\hline$\geq 69$ & $2.638(0.920-8.129)$ & 0.0711 & & \\
\hline \multicolumn{5}{|l|}{ Gender } \\
\hline Male & 1 & & & \\
\hline Female & $0.393(0.061-1.452)$ & 0.1769 & & \\
\hline \multicolumn{5}{|l|}{ ECOG PS } \\
\hline 0,1 & 1 & & & \\
\hline$\geq 2$ & $2.068(0.717-5.826)$ & 0.1730 & & \\
\hline \multicolumn{5}{|l|}{ Clinical T stage } \\
\hline $\mathrm{T} 1 / 2$ & 1 & & & \\
\hline $\mathrm{T} 3 / 4$ & $0.428(0.113-1.734)$ & 0.2203 & & \\
\hline \multicolumn{5}{|l|}{$\mathrm{N}$ stage } \\
\hline N0 & 1 & & & \\
\hline $\mathrm{N} 1 / 2$ & $1.227(0.440-3.676)$ & 0.6975 & & \\
\hline \multicolumn{5}{|l|}{ Number of metastatic sites } \\
\hline 1 & 1 & & & \\
\hline$\geq 2$ & $1.608(0.497-7.147)$ & 0.4499 & & \\
\hline \multicolumn{5}{|l|}{ Bone metastasis } \\
\hline Absent & 1 & & & \\
\hline Present & $2.118(0.694-6.017)$ & 0.1784 & & \\
\hline \multicolumn{5}{|l|}{ MSKCC risk classification } \\
\hline Intermediate & 1 & & & \\
\hline Poor & $1.244(0.415-3.474)$ & 0.6828 & & \\
\hline \multicolumn{5}{|l|}{ Cytoreductive nephrectomy } \\
\hline Yes & 1 & & & \\
\hline No & $2.952(0.890-13.454)$ & 0.079 & & \\
\hline \multicolumn{5}{|l|}{ Early primary renal tumor response } \\
\hline$\geq 10 \%$ shrinkage & 1 & & 1 & \\
\hline Progression or $<10 \%$ shrinkage & $10.956(2.691-74.262)$ & 0.0004 & $8.060(1.644-58.233)$ & 0.0099 \\
\hline \multicolumn{5}{|l|}{ Best response to first-line treatment } \\
\hline Partial response or stable disease & 1 & & 1 & \\
\hline Progressive disease & $26.067(4.111-510.816)$ & 0.0002 & $12.580(1.971-247.566)$ & 0.0054 \\
\hline \multicolumn{5}{|l|}{ Anemia } \\
\hline No & 1 & & & \\
\hline Yes & $1.395(0.494-4.241)$ & 0.5313 & & \\
\hline \multicolumn{5}{|l|}{ Neutrophil-to-lymphocyte ratio } \\
\hline$<3.7$ & 1 & & & \\
\hline$\geq 3.7$ & $2.318(0.755-7.844)$ & 0.1418 & & \\
\hline \multicolumn{5}{|l|}{ Monocyte-to-lymphocyte ratio } \\
\hline$<0.32$ & 1 & & & \\
\hline$\geq 0.32$ & $2.745(0.921-9.159)$ & 0.0699 & & \\
\hline \multicolumn{5}{|l|}{ Platelet-to-lymphocyte ratio } \\
\hline$<217.4$ & 1 & & & \\
\hline$\geq 217.4$ & $1.186(0.426-3.551)$ & 0.7457 & & \\
\hline \multicolumn{5}{|l|}{ C-reactive protein } \\
\hline$<1.56$ & 1 & & & \\
\hline$\geq 1.56$ & $2.098(0.678-6.711)$ & 0.1954 & & \\
\hline
\end{tabular}


Table IV. Correlation between early primary renal tumor response and clinical factors.

\begin{tabular}{|c|c|c|c|}
\hline \multirow[b]{2}{*}{ Clinical factors } & \multicolumn{2}{|c|}{ Early primary renal tumor response } & \multirow[b]{2}{*}{ P-value } \\
\hline & $\begin{array}{l}\geq 10 \% \text { shrinkage } \\
(\mathrm{n}=10)\end{array}$ & $\begin{array}{c}\text { Progression or }<10 \% \\
\text { shrinkage }(n=16)\end{array}$ & \\
\hline Age, years (range) & $62.5(47-81)$ & $70.5(49-78)$ & 0.084 \\
\hline \multicolumn{4}{|l|}{ Gender } \\
\hline Male & 7 & 12 & \multirow[t]{2}{*}{0.7806} \\
\hline Female & 3 & 4 & \\
\hline \multicolumn{4}{|l|}{ ECOG PS } \\
\hline 0,1 & 8 & 9 & \multirow[t]{2}{*}{0.2054} \\
\hline$\geq 2$ & 2 & 7 & \\
\hline \multicolumn{4}{|l|}{ Clinical T stage } \\
\hline $\mathrm{T} 1 / 2$ & 1 & 6 & \multirow[t]{2}{*}{0.1904} \\
\hline $\mathrm{T} 3 / 4$ & 9 & 10 & \\
\hline \multicolumn{4}{|l|}{$\mathrm{N}$ stage } \\
\hline NO & 7 & 5 & \multirow[t]{2}{*}{0.1054} \\
\hline $\mathrm{N} 1 / 2$ & 3 & 11 & \\
\hline \multicolumn{4}{|c|}{ Number of metastatic sites } \\
\hline 1 & 6 & 3 & \multirow[t]{2}{*}{0.0461} \\
\hline$\geq 2$ & 4 & 13 & \\
\hline \multicolumn{4}{|l|}{ Bone metastasis } \\
\hline Absent & 9 & 9 & \multirow[t]{2}{*}{0.0989} \\
\hline Present & 1 & 7 & \\
\hline \multicolumn{4}{|c|}{ MSKCC risk classification } \\
\hline Intermediate & 6 & 9 & \multirow[t]{2}{*}{0.8505} \\
\hline Poor & 4 & 7 & \\
\hline \multicolumn{4}{|l|}{ Anemia } \\
\hline No & 4 & 7 & \multirow[t]{2}{*}{0.8505} \\
\hline Yes & 6 & 9 & \\
\hline NLR (range) & $3.15(1.7-5.6)$ & $5.25(1.8-13.9)$ & 0.0777 \\
\hline MLR (range) & $0.24(0.16-0.54)$ & $0.37(0.17-1.07)$ & 0.0459 \\
\hline PLR (range) & $180.5(112.9-494.4)$ & $240.6(107.7-425.8)$ & 0.6231 \\
\hline CRP (range) & $0.77(0.19-4.03)$ & $2.52(0.13-15.66)$ & 0.0598 \\
\hline
\end{tabular}

ECOG PS, Eastern cooperative oncology group performance status; MSKCC, Memorial Sloan-Kettering Cancer Center; NLR, neutrophil-to-lymphocyte ratio; MLR, monocyte-to-lymphocyte ratio; PLR, platelet-to-lymphocyte ratio; CRP, C-reactive protein.

prognostic factors in Japanese mRCC patients. Previously, Abel et al reported that $10 \%$ primary tumor shrinkage within the first 60 days of treatment predicted a better overall primary tumor response (3). Furthermore, it was demonstrated that an early $10 \%$ decrease in the diameter of the primary renal tumor was predictive of longer OS (4). These findings are consistent with our results. In addition, our results suggest that an early primary tumor response predicts the therapeutic effectiveness of molecularly targeted agents for patients with primary unresectable RCC with synchronous distant metastasis.

The number of metastatic sites was reported to be an important prognostic factor for mRCC (12-14). Yildiz et al reported that the number of sites was a significant prognostic factor for patients receiving sunitinib (15). MLR was previously described as an independent prognostic factor in RCC patients (16). Hutterer et al demonstrated that a high MLR was associated with a 2.3-fold increased mortality risk (17). Our clinical characteristics comparison between the group with $\geq 10 \%$ shrinkage and the group with progression or $<10 \%$ shrinkage shows that the number of metastatic sites and pretreatment MLR tend to be predictive factors for primary renal tumor response.

There were several limitations to our study, including its retrospective design and the limited number of patients from a single institution. A prospective investigation of clinical and molecular characteristics in a large number of patients with primary unresectable RCC with synchronous distant metastasis receiving molecularly targeted therapies is required.

In conclusion, early primary renal tumor shrinkage varies widely among patients with primary unresectable RCC with 
synchronous distant metastasis receiving molecularly targeted therapies. Further research is required for continued progress in the identification of prognostic factors for $\mathrm{mRCC}$.

\section{References}

1. Heng DY, Wells JC, Rini BI, Beuselinck B, Lee JL, Knox JJ, Bjarnason GA, Pal SK, Kollmannsberger CK, Yuasa T, et al: Cytoreductive nephrectomy in patients with synchronous metastases from renal cell carcinoma: Results from the international metastatic renal cell carcinoma database consortium. Eur Urol 66: 704-710, 2014.

2. Hong X, Li F, Tang K, Pang S, Lin G, Li S, Bao J and Tan W: Prognostic value of cytoreductive nephrectomy combined with targeted therapy for metastatic renal cell carcinoma: A meta-analysis. Int Urol Nephrol 48: 967-975, 2016.

3. Abel EJ, Culp SH, Tannir NM, Matin SF, Tamboli P, Jonasch E and Wood CG: Primary tumor response to targeted agents in patients with metastatic renal cell carcinoma. Eur Urol 59: 10-15, 2011.

4. Abel EJ, Culp SH, Tannir NM, Tamboli P, Matin SF and Wood CG: Early primary tumor size reduction is an independent predictor of improved overall survival in metastatic renal cell carcinoma patients treated with sunitinib. Eur Urol 60: 1273-1279, 2011.

5. Capitanio U and Montorsi F: Renal cancer. Lancet 387: 894-906, 2016.

6. Seidel C, Busch J, Weikert S, Steffens S, Bokemeyer C and Grünwald V: Tumour shrinkage measured with first treatment evaluation under VEGF-targeted therapy as prognostic marker in metastatic renal cell carcinoma (mRCC). Br J Cancer 109: 2998-3004, 2013.

7. Miyake H, Miyazaki A, Imai S, Harada K and Fujisawa M: Early Tumor Shrinkage under treatment with first-line tyrosine kinase inhibitors as a predictor of overall survival in patients with metastatic renal cell carcinoma: A retrospective multi-institutional study in Japan. Target Oncol 11: 175-182, 2016.

8. Krajewski KM, Franchetti Y, Nishino M, Fay AP, Ramaiya N, Van den Abbeele AD and Choueiri TK: 10\% Tumor diameter shrinkage on the first follow-up computed tomography predicts clinical outcome in patients with advanced renal cell carcinoma treated with angiogenesis inhibitors: A follow-up validation study. Oncologist 19: 507-514, 2014.

9. Eisenhauer EA, Therasse P, Bogaerts J, Schwartz LH, Sargent D, Ford R, Dancey J, Arbuck S, Gwyther S, Mooney M, et al: New response evaluation criteria in solid tumours: Revised RECIST guideline (version 1.1). Eur J Cancer 45: 228-247, 2009.

10. Smith AD, Shah SN, Rini BI, Lieber ML and Remer EM: Morphology, Attenuation, Size and Structure (MASS) criteria: Assessing response and predicting clinical outcome in metastatic renal cell carcinoma on antiangiogenic targeted therapy. AJR Am J Roentgenol 194: 1470-1478, 2010.

11. van der Veldt AA, Meijerink MR, van den Eertwegh AJ, Haanen JB and Boven E: Choi response criteria for early prediction of clinical outcome in patients with metastatic renal cell cancer treated with sunitinib. Br J Cancer 102: 803-809, 2010.
12. Mekhail TM, Abou-Jawde RM, Boumerhi G, Malhi S, Wood L, Elson P and Bukowski R: Validation and extension of the Memorial Sloan-Kettering prognostic factors model for survival in patients with previously untreated metastatic renal cell carcinoma. J Clin Oncol 23: 832-841, 2005.

13. Négrier S, Escudier B, Gomez F, Douillard JY, Ravaud A, Chevreau C, Buclon M, Pérol D and Lasset C: Prognostic factors of survival and rapid progression in 782 patients with metastatic renal carcinomas treated by cytokines: A report from the Groupe Français d'Immunothérapie. Ann Oncol 13: 1460-1468, 2002.

14. Shinohara N, Nonomura K, Abe T, Maruyama S, Kamai T, Takahashi M, Tatsugami K, Yokoi S, Deguchi T, Kanayama $\mathrm{H}$, et al: A new prognostic classification for overall survival in Asian patients with previously untreated metastatic renal cell carcinoma. Cancer Sci 103: 1695-1700, 2012.

15. Yildiz I, Sen F, Kilic L, Ekenel M, Ordu C, Kilicaslan I, Darendeliler E, Tunc HM, Varol U, Bavbek S and Basaran M: Prognostic factors associated with the response to sunitinib in patients with metastatic renal cell carcinoma. Curr Oncol 20: e546-e553, 2013.

16. Lucca I, de Martino M, Hofbauer SL, Zamani N, Shariat SF and Klatte T: Comparison of the prognostic value of pretreatment measurements of systemic inflammatory response in patients undergoing curative resection of clear cell renal cell carcinoma. World J Urol 33: 2045-2052, 2015.

17. Hutterer GC, Stoeckigt C, Stojakovic T, Jesche J, Eberhard K, Pummer K, Zigeuner R and Pichler M: Low preoperative lymphocyte-monocyte ratio (LMR) represents a potentially poor prognostic factor in nonmetastatic clear cell renal cell carcinoma. Urol Oncol 32: 1041-1048, 2014. 